\title{
Inhaltsübersicht
}

Seite

Bearbeiterverzeichnis..................................................................................................... XI

Literaturverzeichnis ............................................................................................................... XIII

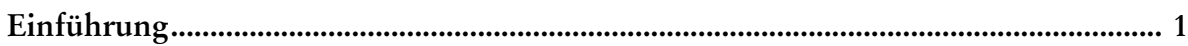

Erstes Buch

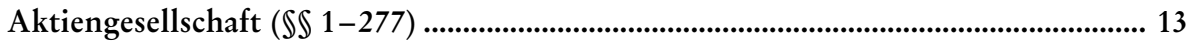

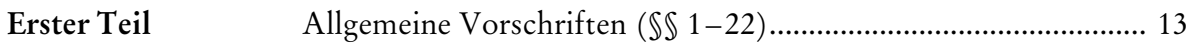

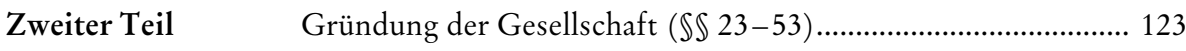

Dritter Teil Rechtsverhältnisse der Gesellschaft und der Gesell-

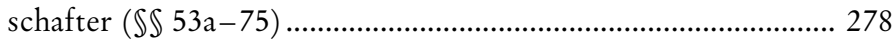

[Anhang zu \57: Aktionärsdarlehen] ......................................... 336

Vierter Teil Verfassung der Aktiengesellschaft $(\mathbb{S} 76-149)$........................... 448

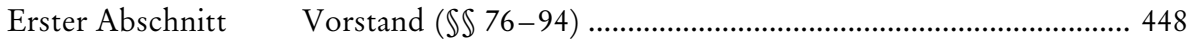

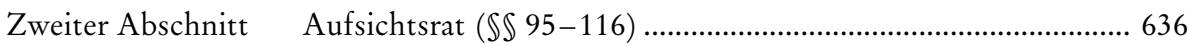

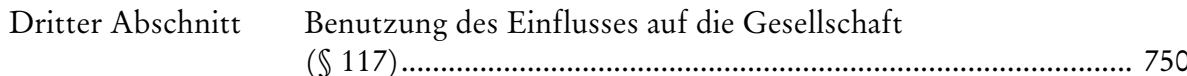

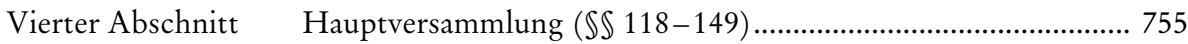

Erster Unterabschnitt

Rechte der Hauptversammlung $\left(\iiint_{118-120)}\right.$.............................. 755

Zweiter Unterabschnitt

Einberufung der Hauptversammlung ( $\left.\iint 121-128\right)$...................... 778

Dritter Unterabschnitt

Verhandlungsniederschrift. Auskunftsrecht (IS 129-132) ............. 837

Vierter Unterabschnitt

Stimmrecht (IS 133-137) ............................................................. 884

Fünter Unterabschnitt

Sonderbeschlu $\beta(\mathbb{1} 138)$................................................................ 929

Sechster Unterabschnitt

Vorzugsaktien obne Stimmrecht (IS 139-141).............................. 932

Siebenter Unterabschnitt

Sonderprüfung. Geltendmachung

von Ersatzansprüchen (IS 142-149)

Fünfter Teil Rechnungslegung. Gewinnverwendung

$(\mathbb{S} 150-178)$

Erster Abschnitt Jahresabschluss und Lagebericht.

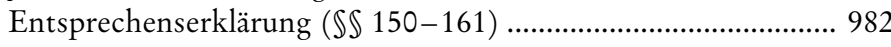


Zweiter Abschnitt Prüfung des Jahresabschlusses (\$S 162-171) ............................. 1012

Erster Unterabschnitt

Prüfung durch Abschlußprüfer (IS 162-169) (aufgehoben) .......... 1012

Zweiter Unterabschnitt

Prüfung durch den Aufsichtsrat (IS 170-171) ............................ 1012

Dritter Abschnitt Feststellung des Jahresabschlusses.

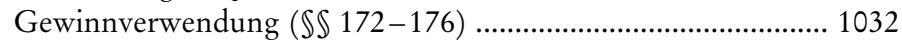

Erster Unterabschnitt

Feststellung des Jahresabschlusses (IS 172-173) ......................... 1032

Zweiter Unterabschnitt

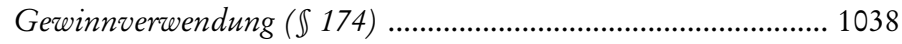

Dritter Unterabschnitt

Ordentliche Hauptversammlung (IS 175-176) ......................... 1040

Vierter Abschnitt Bekanntmachung des Jahresabschlusses

( $\left.\int \mathbb{S} 177-178\right)$ (aufgehoben) 1047

\section{Sechster Teil}

Satzungsänderung. Maßnahmen der Kapital-

beschaffung und Kapitalherabsetzung (\$S 179-240) ................. 1048

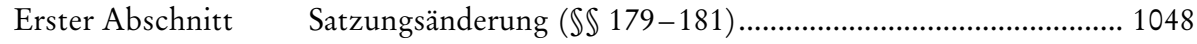

Zweiter Abschnitt Maßnahmen der Kapitalbeschaffung ( $\mathbb{S} 182-221)$.................... 1078

Erster Unterabschnitt

Kapitelerböhung gegen Einlagen (IS 182-191) ........................... 1078

Zweiter Unterabschnitt

Bedingte Kapitalerböbung ( $\iiint_{192-201)}$.................................... 1139

Dritter Unterabschnitt

Genehmigtes Kapital (SS 202-206) …........................................ 1178

Vierter Unterabschnitt

Kapitalerböhung aus Gesellschaftsmitteln (SS 207-220) ............. 1207

Fünfter Unterabschnitt

Wandelschuldverschreibungen. Gewinnschuldver-

schreibungen (\221)

Dritter Abschnitt Maßnahmen der Kapitalherabsetzung (\$S 222-240).................. 1263

Erster Unterabschnitt

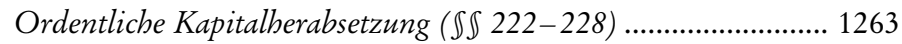

Zweiter Unterabschnitt

Vereinfachte Kapitalherabsetzung (IS 229-236) ........................ 1287

Dritter Unterabschnitt

Kapitalherabsetzung durch Einziebung von Aktien.

Ausnabme für Stückaktien (IS 237-239)...

Vierter Unterabschnitt

Ausweis der Kapitalherabsetzung (\240). 
Siebenter Teil Nichtigkeit von Hauptversammlungsbeschlüssen und des festgestellten Jahresabschlusses.

Sonderprüfung wegen unzulässiger Unterbewertung $(\mathbb{S} 241-261 \mathrm{a})$

Erster Abschnitt Nichtigkeit von Hauptversammlungsbeschlüssen $(\mathbb{S} 241-255)$

Erster Unterabschnitt

Allgemeines(SS 241-249)

Zweiter Unterabschnitt

Nichtigkeit bestimmter Hauptversammlungsbeschlüsse

( $\left.\iint 250-255\right)$

Zweiter Abschnitt Nichtigkeit des festgestellten Jahresabschlusses

( $\mathbb{S} 256-257)$

Dritter Abschnitt Sonderprüfung wegen unzulässiger Unterbewertung

$(\mathbb{S} 258-261 \mathrm{a})$ 1402

Achter Teil Auflösung und Nichtigerklärung der Gesellschaft

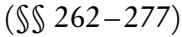
1417

Erster Abschnitt Auflösung (\$S 262-274) 1417

Erster Unterabschnitt

Auflösungsgründe und Anmeldung (SS 262-263)

Zweiter Unterabschnitt

Abwicklung (\$S 264-274) 1426

Zweiter Abschnitt Nichtigerklärung der Gesellschaft

$(\mathbb{S} 275-277)$ 1461

\section{Zweites Buch}

Kommanditgesellschaft auf Aktien ( $\left.\iint 278-290\right)$ 1469

Drittes Buch

Verbundene Unternehmen $(\mathbb{S} 291-393)$....................................................................... 1505

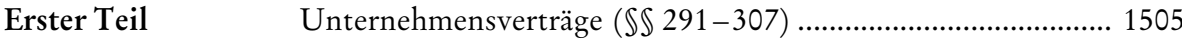

Erster Abschnitt Arten von Unternehmensverträgen ( $\mathbb{S} 291-292)$...................... 1505

Zweiter Abschnitt Abschluß, Änderung und Beendigung von Unternehmensverträgen ( $\left.\int \mathbb{S} 293-299\right)$ 1525

Dritter Abschnitt Sicherung der Gesellschaft und der Gläubiger $(\mathbb{S} 300-303)$ 1564

Vierter Abschnitt Sicherung der außenstehenden Aktionäre bei Beherrschungs- und Gewinnabführungsverträgen $(\mathbb{S}$ 304-307) 
Zweiter Teil Leitungsmacht und Verantwortlichkeit bei

Abhängigkeit von Unternehmen (\$S 308-318)......................... 1591

Erster Abschnitt Leitungsmacht und Verantwortlichkeit bei Bestehen

eines Beherrschungsvertrags ( $\mathbb{S} 308-310)$.................................. 1591

Zweiter Abschnitt Verantwortlichkeit bei Fehlen eines

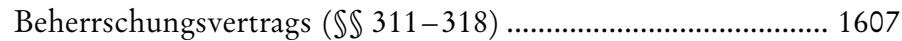

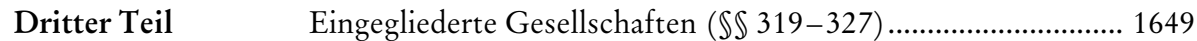

Vierter Teil Ausschluss von Minderheitsaktionären

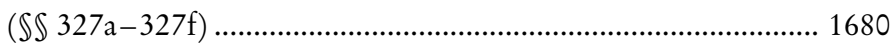

Fünfter Teil Wechselseitig beteiligte Unternehmen $(\mathbb{S} 328)$........................... 1712

Sechster Teil Rechnungslegung im Konzern

$(\mathbb{S}$ 329-393) (aufgehoben) ........................................................ 1715

Viertes Buch

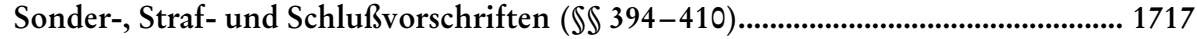

Erster Teil Sondervorschriften bei Beteiligung von

Gebietskörperschaften $(\mathbb{S} 394-395)$......................................... 1717

Zweiter Teil Gerichtliche Auflösung (\$S 396-398)......................................... 1726

Dritter Teil Straf- und Bußgeldvorschriften. Schlußvorschriften

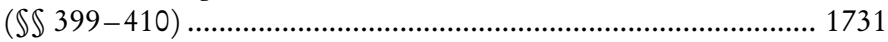

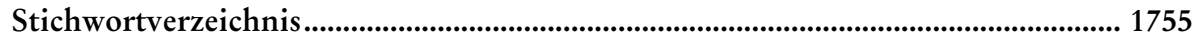

